\title{
Recorrer esta distancia. Notas sobre el exilio
}

\author{
Edmundo GARRIDO AlARCÓN \\ egarrido75@gmail.com
}

Estoy separado de mí por la distancia en que yo me encuentro; el muerto está separado de la muerte por una gran distancia.

Pienso recorrer esta distancia descansando en algún lugar.

De espaldas en la morada del deseo,

Sin moverme de mi sitio -frente a la puerta cerrada, Con una luz de invierno a mi lado.

(Jaime Sáenz, Recorrer esta distancia)

Una cierta mirada es el título de una recopilación de ensayos críticos publicados en la mítica revista mexicana Vuelta, dirigida por Octavio Paz. En una cierta mirada confluyen las palabras teatro y teoría. Si teatro, el lugar, significa mirador, teoría es mirada. Si el teatro, en palabras de Ortega y Gasset, es la "metáfora visible", la teoría (literaria) ha evolucionado en un complejo campo analítico que no se circunscribe a la Teoría de la Literatura como se enseña en las academias. Sin pretender un acercamiento que se haga cargo de ese coto vedado, estas notas sobre el exilio se proponen como una cierta mirada sobre el exilio, esa forma de distancia. Un paso por ciertas visiones filosóficas, un tanto pesadas, nos permitirán establecer el portal de acceso a esta mirada abierta y multidisciplinar a las respuestas literarias al exilio.

Todo exilio es político. En cuanto forma-de-vida como lo entiende el filósofo italiano Giorgio Agamben, es decir "una vida que no puede separarse nunca de su forma", donde la manera de habitar la ciudad es "una vida política, es decir orientada según la idea de felicidad y que se aglutina en una forma-de-vida" (2001: 13 y 17) donde retoma la tesis de Foucault según la cual la política implicada en la vida se ha convertido en biopolítica. Siguiendo las ideas planteadas en la recopilación de 
textos reunidos en el libro de Agamben Medios sin fin nos encontramos que el pensamiento de diversos autores en torno a la política, como Walter Benjamin o Hannah Arendt, pasando por Martin Heidegger y Guy Debord, sirven al filósofo italiano para articular ideas como la actualidad del "estado de excepción", la figura del refugiado como "paradigma de una nueva conciencia histórica" (Agamben 2001: 21) y "el campo [de concentración] no como un simple hecho histórico o una anomalía perteneciente al pasado (aunque eventualmente, siga estando presente todavía), sino, en algún modo, como la matriz oculta, el nomos del espacio político en que aún vivimos" (Agamben 2001: 37). En este sentido es central la división en dos formas de problematizar la relación entre Estado e historia, cuando se postula que uno u otro toca a su fin, donde "el plano de inmanencia sobre el que se construye la nueva experiencia política es la extrema expropiación del lenguaje llevada a efecto por el Estado espectacular" (Agamben 2001: 94). Es en el lenguaje, a través de la idea de comunicación, que se estructura la nueva situación de los "medios sin fin" que dan título al conjunto: "Lo que impide la comunicación es, pues, la comunicabilidad misma; los hombres están separados por aquello que les une" (Agamben 2001: 98). Este compacto conjunto de referencias a uno de los más importantes filósofos contemporáneos nos permite comprender la esencia política del exilio, su relación de distancia material de la vida, bios, con la polis, el Estado-nación (regido por una legislación, nomos, propia), donde la nación-nacionalidad está en directa relación con el nacimiento, y la forma originaria de entender el exilio es la imposibilidad de habitar el lugar donde se ha nacido y de hablar en la lengua materna.

Justamente por la contundencia de esta constatación, para unos estudios literarios o que se dirigen a los aspectos del campo literario de los textos, las connotaciones y los matices políticos, en su dimensión ideológica concreta, polarizada y comprometida, son lo menos interesante. El carácter político del exilio es inevitable desde el momento en que tratamos con una problemática de cambio espacial, el exilio es el estar fuera de la polis, y lingüístico a partir de una idea de convergencia de origen que contiene tanto el lugar como la palabra. Es político en cuanto, desde el ostracismo, el exilio es una forma de sacar al individuo o individuos del ejercicio político de la comunidad a la que pertenece y que le pertenece, que le es propia. Dice María Zambrano: "Algo encuentra [el refugiado] dentro de lo cual depositar su cuerpo que fue expulsado de ese lugar primero, patria se le llama, casa propia, de lo propio, aunque fuese el lagar de la propia miseria. Y en el destierro se siente sin tierra, la suya, y sin otra ajena que pueda sustituirla" (2004: 31-32). Las escrituras del exilio surgen de esta falta, de esta ausencia: "Y eso es lo que la caracteriza más que nada: no tener lugar en el mundo, ni geográfico, ni social, ni político, ni -lo que decide en extremo para que salga de él ese desconocido- ontológico. No ser nadie, ni un mendigo: no ser nada. Ser tan sólo lo que no puede dejarse ni perderse, y en el exiliado más que en nadie" (Zambrano 2004: 36). Podemos seguir el proceso inverso, y en muchos casos complementario, de la experiencia del exilio, el regreso de una de las más grandes pensadoras españolas en el "Relato prologal" que abre la selección de textos de su obra, Esencia y hermosura, realizada por José-Miguel Ullán: "En 1986, ya asentada en Madrid, cuenta cómo logró volver: 'Yo vine, para poderlo soportar, mirando la luz. Cuando, por una luz anaranjada supe que ya sobre- 
volaba España, entonces, sí, entonces me dio un vuelco el corazón. [...] Fuera de mí [España] no ha estado nunca. Yo dentro de ella no he podido estar. Es una situación paradójica, que yo ahora espero que deje de serlo. No borrar lo que ha sido, no borrar el exilio, quizá seguir siendo exiliada en España sería una gran hazaña, digo yo, moral"" (Ullán 2010: 69). La distancia y el camino entre el adentro y el afuera, es decir, la temporalidad, parecen ser ejes básicos de este fenómeno.

Sin pretender entrar en la trampa de una estructura, basada en arquetipos etnocéntricos, podemos plantear, evitando la ilusión de ser exhaustivos, algunas de las formas en que el exilio se enuncia en los textos literarios o formas artísticas de un corpus amplio y abierto de obras occidentales de la modernidad, asumiendo el riesgo de ambas nociones difusas. Buscamos las "respuestas literarias al exilio" en palabras del comparatista Claudio Guillén (2007: 29). Pero no para dar cuenta de estas, para realizar una síntesis, resultado de un proceso dialéctico. A partir de la dialéctica negativa planteada por Adorno, se proponen una serie de caracteres exentos de jerarquía o estructura unívoca. Una metáfora espacial puede resultar de utilidad: si entendemos las escrituras del exilio como una galaxia de posibles respuestas literarias a este fenómeno, podemos diferenciar una serie de constelaciones de diversas dimensiones y, en muchos casos, superpuestas o con zonas difusas. Para esto nos planteamos coordenadas espaciales, temporales y lingüísticas. No pensando en categorías literarias convencionales sino a partir del fenómeno vital del exilio, como forma-de-vida, podemos plantear las siguientes dimensiones que reflejan las distintas expresiones del exilio:

El cuerpo en el espacio del exilio desgrana, al menos, cuatro situaciones convencionales que son el destierro, el insilio, el campo y el lugar del meteco. Luego según la cuarta dimensión está el des-tiempo del exilio. Respecto a la lengua del exilio, encontramos que suele haber un cambio de la lengua materna o bien lo que hemos llamado el afuera del lenguaje. La palabra del exilio suele tener como referente la denuncia, la nostalgia o lo no-dicho. Los modos de escritura del exilio suelen ser los de la ficción o el testimonio autobiográfico. Por último, la recepción de estos textos se puede dividir entre lecturas internas y lecturas externas. Profundizaremos en cada uno de estos enunciados.

Esta lista que no pretende ser exhaustiva tampoco espera ser original, ni forzar una originalidad banal. Por lo mismo sólo incidiremos en mayor o menor medida en algunas categorías quizás poco tomadas en cuenta hasta ahora o aspectos menos tópicos de los lugares (semánticos) del exilio.

La situación del cuerpo en el espacio del exilio se puede experimentar de tres formas generales: a) El destierro propiamente tal, la expulsión física o bien la necesidad de huir del país por peligro de pérdida de libertades mínimas o de la vida misma. b) El "insilio" o exilio interior, según el cual, sin abandonar el espacio físico habitual, el individuo se repliega sobre sí mismo abandonando su figuración pública. c) La experiencia del campo de concentración, donde la persona es detenida y tiene reducidas sus libertades.

Estas tres experiencias coinciden en la figura del refugiado destacada por Arendt y citada por Agamben, en el campo filosófico y también aprovechado por la sociología, por ejemplo, en los trabajos recientes de un preciso observador de los cam- 
bios actuales, Zygmunt Bauman. Sólo como breve referencia, en textos como Archipiélago de excepciones y Confianza y temor en la ciudad: Vivir con extranjeros se aclara la figura del refugiado clásica, carente de Estado, en el novedoso sentido de "fuera de la ley" (hors du nomos), es decir parias (Bauman 2008: 32). Siendo condiciones la imposibilidad de salir de este "estado" no-Estado y, en muchos casos, del campo de refugiados (que se desliza al campo de concentración en varios niveles prácticos y semánticos) con la consecuente suspensión del devenir temporal. El campo sería el verdadero no-lugar descrito por Marc Augé, hasta el punto de que no contamos -o al menos no tenemos noticia de ellos- con relatos de estos campos. Por condiciones de aislamiento lingüístico (comundidades chinas, rumanas o pakistaníes en España, por citar un ejemplo cercano), económicas (concentración en oficios específicos) y propiamente urbanas (comunidades de ayuda y solidaridad que se sitúan en barrios de rentas bajas), opera la lógica del ghetto, y el verdadero campo del exilio masivo es la ciudad contemporánea. En estas condiciones surgen nuevos fenómenos como la ambivalencia entre mixofilia y mixofobia, siendo dos polos de la tolerancia a la mezcla cultural, étnica y social en el espacio urbano (Bauman 2006: 36). Bauman alerta del círculo vicioso que generan ciertas políticas urbanísticas segregacionistas cuando "la fusión que requiere el entendimiento mutuo sólo puede provenir de la experiencia compartida; y compartir la experiencia es inconcebible si antes no se comparte el espacio" (Bauman 2006: 38). Es decir, atender al espacio urbano es esencial para un acercamiento amplio y atento a condiciones de identidad, lengua y cultura de la condición del exiliado, ese refugiado que necesita y solicita refugio y cuya situación metafóricamente puede ser llamada a la intemperie, siendo esta también una imagen espacial. En los estudios sobre literatura y artes en concreto, el concepto de extraterritorialidad, acuñado por George Steiner, nos permite vincular esta condición al campo literario:

Un gran escritor a quien las revoluciones sociales y las guerras expulsan de lengua en lengua es un símbolo cabal de la era del refugiado. Ningún otro exilio puede ser más radical, ninguna otra hazaña de adaptación a una nueva vida puede ser más exigente. Nos parece adecuado que los que producen arte en una civilización casi bárbara, que ha despojado de su hogar a tantas personas y arrancado de lenguas y gente de cuajo, sean también poetas sin casa y vagabundos atravesando diversas lenguas. Excéntrico, hosco, nostálgico, deliberadamente fuera de su tiempo -tal como aspira a ser y frecuentemente lo es-, Nabokov no deja de ser profundamente, en virtud de su extraterritorialidad, un hombre de su tiempo y uno de sus más destacados portavoces. (Steiner 2001: 24)

Steiner establece de manera limpia la relación indisoluble entre espacio, tiempo y lengua que intentamos modular para el campo literario. Sin embargo, no podemos olvidar que este campo se circunscribe dentro de otro más amplio, el cultural, donde pasamos del individuo a la comunidad, aunque su experiencia luego sea traducida en obras más o menos colectivas. Esto es lo que destaca Edward Said en su ensayo "Reflexiones sobre el exilio", poniendo el acento en el cambio histórico de este fenómeno: "[...] la diferencia entre los exiliados anteriores y los de nuestro tiempo es (podemos hacer énfasis en ello) la escala: nuestro tiempo -con su guerra moder- 
na, su imperialismo y las ambiciones cuasiteológicas de los gobiernos totalitarioses ciertamente la era del refugiado, de la persona desplazada, de la inmigración masiva" (Said 2005: 180). La reflexión cuantitativa suele ser ociosa en la teoría literaria, sin embargo, surge un curioso acuerdo entre Steiner y Said, ya que los autores no podrían ser "portavoces" sin un contexto social fuertemente definido. Es lo que también trata Hans Magnus Enzensberger en su ensayo La gran migración (1992), cuando, a propósito de estos grandes desplazamientos, destaca la inversión del imaginario del refugiado a través del miedo al emigrante que desemboca en la xenofobia y el fortalecimiento de las diferencias nacionales.

Quizás sólo la condición retraída, en sí, en el espacio de la casa, del insilio, queda fuera de esta configuración, aunque sus características afloran tanto en la modulación del lenguaje de lo no-dicho bajo vigilancia como en la recepción de su obra en espacios opuestos (manuscritos sacados clandestinamente para ser publicados en el exterior cuando lo convencional es que los textos de exiliados sean internados en los países de origen).

Por último, la banalización de las experiencias del cuerpo en el exilio, en cuanto escenificación del mismo o espectáculo (en términos de Guy Debord) en cierta supuesta posmodernidad se puede ver, por ejemplo, en París no se acaba nunca de Vila-Matas, donde el autor se presenta como exiliado directamente en el Café de Flore, no en París. Además, viviendo de los envíos de dinero de su padre y por razones meramente literarias, no políticas, aunque relacionado con los antifranquistas, y situacionista sin haber leído a Debord. Es decir el meteco total, en el sentido francés del término, originalmente griego y que significa simplemente extranjero, que fue usado de manera xenófoba por los nacionalistas desde Maurras en el XIX, pero que en el campo cultural incide en el arribismo de ciertos personajes propios de la Comedia humana de Balzac, como Rastignac, y que el autor contemporáneo español escenifica con tanta ironía. Por otro lado, Enrique Lihn, poeta chileno seguidor de Parra en el desmontaje del aura lírica, denunciaba, allá por la segunda mitad del siglo pasado, esta actitud tanto en Rubén Darío como en Vicente Huidobro. Este movimiento es el del intelectual de la periferia cultural, sea Chile o la España franquista, que busca, desesperada y, a veces, patéticamente, ubicarse en el centro, dejando de lado su propia identidad, si es necesario. Por ejemplo, Huidobro comienza a firmar "Vincent" y a escribir en francés, como el peruano César Moro, o VilaMatas que se disfraza, fuma en pipa, usa gafas falsas y aparenta leer en su ficticio exilio del Café de Flore. Lo que no cambia es el lugar, París, aunque el personaje de Vila-Matas reconoce que debió haber ido a Nueva York. Lihn estuvo tanto en París como en Nueva York, en distintas épocas, antes y durante la dictadura chilena.

A través del concepto de nostalgia, etimológicamente la enfermedad del regreso, se puede entender la salida del tiempo que implica el destierro. El des-tiempo en el que el exiliado está condenado a una temporalidad ambigua, en la que conviven pasado y presente (todos lo estamos según Proust, pero en el exiliado esta condición se potencia). Es lo que Julia Kristeva expresa con claridad al comienzo de su libro Extranjeros para nosotros mismos: "No pertenecer a ningún lugar, ningún tiempo, ningún amor. El origen perdido, el imposible enraizamiento, la memoria que se sumerge, el presente en suspenso" (1991: 16). Es decir, el desplazamiento espacial 
que provoca una temporalidad doble realmente desemboca en un destiempo, en su suspensión, por cuanto el devenir, la vida, no se vive en ninguno de los dos.

La lengua del exilio, el habla, tanto si se cambia de espacio físico como si no, se suele ver afectada llegando algunos autores a variar la usada como forma de expresión de sus obras. El más extendido tópico es el de la lengua materna como la patria del exiliado. Lo único de su patria que ha llevado con él. El ejemplo de Mircea Eliade es significativo por cuanto escribe su prosa de investigación en las lenguas de difusión científica de los lugares donde trabaja (francés, inglés) y, sin embargo, escribe su ficción en rumano. Este tópico, fundado en una concepción nacionalista propia de la Europa moderna, va a ser severamente cuestionado tanto en sus aspectos ideológicos como propiamente lingüísticos por una serie de autores afectados por la inmensa cantidad de desplazamientos que involucraron a diversas comunidades durante el siglo XX. Un ejemplo del mismo entorno de Eliade, es decir de los exiliados de los regímenes totalitarios de izquierdas de la posguerra de la segunda mitad del siglo XX, es el que da Milan Kundera en su texto "El exilio liberador según Vera Linhartova" incluido en su libro de ensayos Un encuentro. Aquí se ve el desplazamiento del escritor como guardián de su lengua a una situación menos estática y sin carga nacionalista: "el escritor no es prisionero de una única lengua" dice Vera Linhartova (Kundera 2009: 130-131), cuyas "simpatías nómadas" son, entre otros, Nabokov, Beckett, Stravinsky, Gombrowicz.

Luego, dentro de este mismo contexto, pero con matices que le dan carta de identidad, la idea de un estar en el afuera del lenguaje también es relevante en cuanto distintos pensadores han situado ese afuera en la muerte o en la nada, y la distancia forzada conlleva ese extrañamiento en la vida cotidiana. Es decir, un lenguaje unheimlich, para volver al concepto freudiano que recuerda Kristeva (1991: 221223). La experiencia de vivir fuera del lenguaje materno, se cambie el lenguaje de expresión escrita o no, y la tematización de esta problemática en los textos han generado numerosos testimonios y ficciones. Sin embargo existen al menos dos propuestas para pensar esta dimensión que, sin ser exactamente contrapuestas, son más sugerentes que los problemas idiomáticos de comunicación y asentamiento al uso.

Por una parte Julia Kristeva lleva lo extranjero, por vía del lenguaje, al interior: "El extranjero está en nosotros. Y cuando huimos o combatimos al extranjero, luchamos contra nuestro inconsciente, ese 'impropio' de nuestro 'propio' imposible. Delicadamente, analíticamente Freud no habla de los extranjeros: nos enseña a detectar la extranjería en nosotros. [...] El extraño está en mí, por lo que todos somos extranjeros. Si yo soy extranjero, no existen los extranjeros" (1991: 233). Por otra parte Jacques Derrida plantea que el lenguaje propio siempre es del otro, desplazando el problema desde la relación genitiva con el lenguaje (materno), y por tanto inconsciente, a una relación de proximidad con el otro, dialógica y por tanto política en el sentido lato que venimos usando del término. "Cualquiera debe poder declarar bajo juramento, entonces: no tengo más que una lengua y no es la mía, mi lengua 'propia' es inasimilable para mí. Mi lengua, la única que me escucho hablar y me las arreglo para hablar, es la lengua del otro" (Derrida 1997: 39) Donde, explica, "el de no significa tanto propiedad como procedencia: la lengua está en el otro, viene del otro, es la venida del otro" (1997: 109). Es un problema de distancia y desplaza- 
miento, de recorrido. Según Kristeva negamos la distancia, según Derrida decimos como una forma de recorrer esa distancia. Se cruza la idea de yo soy otro con la de mi lengua es la de otro, y se abre una inmensa cantidad de posibles líneas de pensamiento respecto a conceptos como la identidad, el individuo, el cuerpo y su relación con el lenguaje. Sobre la forma-de-vida de la que habla Agamben, en su aspecto más amplio.

Estos desplazamientos en las coordenadas básicas del asentamiento del ser en el mundo y su palabra inciden en su forma de decirlo. La expresión de la situación de exilio que puede contemplar la más prosaica denuncia de una situación concreta, la nostalgia expresada como enaltecimiento del espacio abandonado y el tiempo pasado, o bien, comparación del estado anterior con el actual, incluso, en muchos casos con el agradecimiento de la hospitalidad, o, finalmente, en ciertas circunstancias, estrategias más elaboradas como lo no-dicho, en especial en situaciones, como el insilio o el campo, en que la situación de desarraigo separa al individuo del Estado pero no lo protege o aleja de su poder y su venganza.

Estas expresiones se pueden escribir desde diversos lugares de la enunciación. La ficción, la literatura propiamente, frente al testimonio, más que autobiográfico, legal, para algunos, como la pensadora argentina Beatriz Sarlo, puede dar cuenta de realidades complejas, como las torturas y exilios vividos por miles en la Argentina: "un narrador siempre piensa desde afuera de la experiencia, como si los humanos pudieran apoderarse de la pesadilla y no sólo padecerla" (Sarlo 2005: 166). Es decir, otra vez ese exilio, el afuera de la experiencia, resulta positivo para el discurso, es lo que permite verla con distancia. Sin embargo, una mirada rápida a la producción literaria, por ejemplo la producida a consecuencia del exilio español, republicano, posterior a 1939, muestra que una importante cantidad de textos, siendo literarios, se deslizan o inclinan hacia el testimonio, quizás buscando su validez en este y no tanto en sus valores propiamente literarios. Tanto es así que se puede diferenciar entre escritores en el exilio, Alberti, Cernuda, Zambrano, Aub, y un largo etcétera de memorias de personas o personajes históricos que tienen un estatuto literario bastante dispar. El yo que busca el conocido pacto autobiográfico se expresa en diarios, memorias, etc., y en muchos casos de manera fragmentaria. Fuera del contexto español es de notar un fenómeno que incide en un elemento paratextual clave tanto en la identidad del autor como en su recepción extraterritorial: su nombre, seudónimo o máscara. Este es cambiado por múltiples razones en las que no podemos extendernos. Por citar algunos ejemplos, del sutil Ionescu a Ionesco, al anagrama de Antschel por Celan, de Markus Rothkowitz a Mark Rothko, el griego Elia Kazan, etc.

Finalmente, la recepción de los textos del exilio se puede dividir, mientras duran las condiciones de fuerza, entre interior y exterior, donde se aplican de modos diversos y complejos gran parte de los aspectos que hemos visto. Después de pasadas estas condiciones de poder también existen fenómenos interesantes de estudiar desde esta perspectiva. Por ejemplo, la sobrepoblación de memorias, novelas y películas (basadas en las anteriores o no) sobre la guerra civil española y la inmediata posguerra, que han caracterizado, y muchas veces opacado, parte importante de la producción narrativa de la España democrática sin que se haya llegado a una "gran novela de la guerra", idea ansiada por los editores pero difícil de discernir, de forma 
no instrumentalizada, por los críticos. Por ejemplo, la experiencia lectora de la poesía política de Neruda ha sido muy diferente en los años de la polarización de la guerra fría en general, en particular cuando sus libros se compraban en negro en ciertas librerías de la España franquista, o en el actual desencanto con los grandes relatos totalitarios.

En contraste con el orden dimensional desarrollado hasta aquí, hay otros más asentados en los estudios literarios comparados en torno a la idea del exilio como tema que no pude obviarse en una panorámica sobre las respuestas literarias del fenómeno. "El exilio no es una cosa material, es una cosa moral" dice Victor Hugo sobre su destierro de Guernsey (2007: 26), y es un reflejo o topos del exilio como tema, donde la experiencia deja de ser relevante y toman preponderancia las relaciones intertextuales con la tradición. En este sentido, sin duda la obra de referencia es la de Claudio Guillén en general y en particular su ensayo "El sol de los desterrados: literatura y exilio" (2007: 29-97). El ejercicio comparatista distingue una serie de procesos entre los que los principales son la tematización, la metaforización, la literalización y la ampliación de sentidos (Guillén 2007: 93). Sin embargo, estos procesos, indiferentes a lo propio del exilio como distancia, sirven para decantar muchos de los aspectos que hemos visto, como el uso amplio del término, el destiempo, el bilingüismo, las tensiones entre exilio "triste" y cosmopolitismo, desde los cínicos hasta los emigrados producto de la revolución francesa, los efectos de la nacionalización de la cultura, etc. (Guillén 2007: 64-85). Guillén toma como eje comparativo la polaridad positiva o negativa con la que se encara el exilio, sea para tematizarlo, testimoniarlo o ficcionarlo. El análisis valorativo le permite sobrepasar sin estridencias los problemas de comparación entre modulaciones muy diferentes del exilio a través de la historia y los géneros (Guillén 2007: 30). Como dice Edward Said, "El exilio es algo curiosamente cautivador sobre lo que pensar, pero terrible de experimentar" (Said 2005: 179).

Para terminar esta mirada sobre el exilio vamos a pasar por el campo textual del pensamiento en torno a la poesía, partiendo de la concepción de Miguel Casado de la poesía como pensamiento. En su ensayo "La memoria del fuego", José Ángel Valente cita extensamente a Edmond Jabès en su memorable entrevista con Marcel Cohen, Del desierto al libro, "Tal vez eran necesarios el éxodo, el exilio, para que la palabra cortada de toda palabra -y confrontada así al silencio- adquiriese su verdadera dimensión [...]" (Valente 2000: 254). El límite físico del exilio, el límite con el desierto, configura un límite del decir, más allá de todo lenguaje, o monolingüismo en términos derridianos. Con la ausencia de lenguaje, el silencio, "empieza la palabra poética en el punto o límite extremo en que se hace imposible el decir" (Valente 2000: 255). Palabra poética, entonces, palabra de exilio. Luego, en El libro de la hospitalidad, el mismo Jabès dirá: "J'ai, du livre, fait mon lieu" (He hecho, del libro, mi lugar) (Jabès 2002: 78). Recorrer esta distancia nos permite pensar una poética de la escritura como una forma de exilio en el libro. Es un vínculo que Eduardo Milán ha formulado en Un ensayo sobre poesía: "El estar de la palabra poética es un estar análogo al estar exiliado por su condición sin raíz" (Milán 2006: 30). Para dar forma a un círculo que no se cierra, el del exilio y el retorno pero también el de la amistad, podemos decir que esta mirada sobre la distancia ha sido escri- 
ta a la luz del pensamiento poético y la experiencia de Eduardo Milán, poeta y crítico uruguayo exiliado en México y autor de los ensayos reunidos en el libro mencionado al comenzar, Una cierta mirada. Siempre atento a las poéticas de ambas orillas, dejó constancia de su intensa relación literaria y personal con el poeta español José-Miguel Ullán, también exiliado durante años, en un libro de título topográfico, El camino Ullán. Quizás sea la amistad - políticas de la amistad diría Derrida- el lugar del refugiado al recorrer esta distancia.

\section{BIBLIOGRAFÍA}

AGAMBEN, Giorgio (2001): Medios sin fin. Notas sobre la política. Valencia: Pre-Textos.

BAUMAN, Zygmunt (2006): Confianza y temor en la ciudad. Vivir con extranjeros. Barcelona: Arcadia.

- (2008): Archipiélago de excepciones. Madrid: Katz.

DERRIDA, Jacques (1997): El monolingüismo del otro o la prótesis de origen. Buenos Aires: Manantial.

ENZENSBERGER, Hans Magnus (1992): La gran migración. Barcelona: Anagrama.

GUILLÉN, Claudio (2007): Múltiples moradas. Ensayo de literatura comparada. Barcelona: Tusquets.

HUGO, Victor (2007): El exilio. Ciudad de México: UNAM.

JABÈS, Edmond (2002): El libro de la hospitalidad. Ciudad de México: ALDUS.

KRISTEVA, Julia (1991): Extranjeros para nosotros mismos. Barcelona: Plaza \& Janés.

KUNDERA, Milan (2009): Un encuentro. Barcelona: Tusquets.

MILÁN, Eduardo (2006): Un ensayo sobre poesía. Ciudad de México: Ácrono Producciones / Libros del Umbral.

SÁENZ, Jaime (2004): Recorrer esta distancia. Antología poética. Ciudad de México: FCE.

SAID, Edward (2005): Reflexiones sobre el exilio. Ensayos literarios y culturales. Barcelona: Debate.

SARLO, Beatriz (2005): Tiempo pasado. Cultura de la memoria y giro subjetivo. Una discusión. Buenos Aires: Siglo XXI.

STEINER, George (2001): Extraterritorial. Ensayos sobre literatura y revolución lingüística. Madrid: Siruela.

ULLÁN, José-Miguel (2010): "Relato prologal. Señales debidas", en María Zambrano, Esencia y hermosura. Antología. Madrid: Galaxia Gutenberg.

VALENTE, José Ángel (2000): Variaciones sobre el pájaro y la red precedido de la piedra y el centro. Barcelona: Tusquets.

ZAMBRANO, María (2004): Los bienaventurados. Madrid: Siruela. 